\title{
The effect of pycnogenol on patients with dysmenorrhea using low-dose oral contraceptives
}

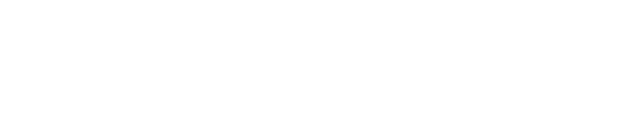

Hugo Maia Jr

Clarice Haddad

Julio Casoy

Centro de Pesquisa e Assistência em Reprodução Humana (CEPARH), Salvador, Bahia, Brazil
Correspondence: Hugo Maia Jr CEPARH, 35 Rua Caetano Moura,

Salvador, Bahia, Brazil

Tel +55 7l 32478216

Fax +55 7I 32343442

Email ceparh@uol.com.br
Objective: Menstrual symptoms such as dysmenorrhea usually occur during the hormone-free interval in oral contraceptive users. Progestin withdrawal activates NF- $\kappa \mathrm{B}$ transcription factor, which upregulates both vascular endothelial growth factor (VEGF) and Cox-2 expression in the endometrium. The use of natural NF- $\mathrm{KB}$ inhibitors such as pycnogenol may block this response, improving dysmenorrhea.

Patients and methods: Twenty-four patients with severe dysmenorrhea were allocated to one of two treatment groups. In Group $A(n=13)$, women were treated with an oral contraceptive containing $15 \mu \mathrm{g}$ of ethinyl estradiol and $60 \mathrm{mg}$ of gestodene (Adoless ${ }^{\circledR}$ ) in a 24/4 regimen for three consecutive cycles. Women in Group B $(n=11)$ used the same contraceptive regimen together with $100 \mathrm{mg}$ of pycnogenol (Flebon ${ }^{\circledR}$ ) continuously for 3 months. Pain scores were graded using a visual analog scale (VAS) before and during the hormone-free interval at the end of the third treatment cycle.

Results: Before treatment, VAS pain scores for dysmenorrhea were 8 and 9 in Groups A and B, respectively. However, by the end of the third treatment cycle, pain scores had decreased significantly $(P<0.05)$ both in groups A and B. The final pain scores were 6 in Group A and 2 in Group B, a difference that was statistically significant $(P<0.0001)$. In Group B, 27\% of the patients became pain-free, while in Group A, none of the women reported complete disappearance of this symptom. The number of bleeding days was also lower in Group B.

Discussion: Pycnogenol effectively decreased pain scores and the number of bleeding days when administered concomitantly with a low-dose $24 / 4$ oral contraceptive containing gestodene.

Keywords: gestodene, hormone-free interval, pain

\section{Introduction}

Menstrual symptoms such as dysmenorrhea usually occur during the hormone-free interval in oral contraceptive users following progestin withdrawal, which activates the NF- $\kappa \mathrm{B}$ transcription factor in the endometrium. This leads to an increase in the expression of both cyclooxygenase and inflammatory cytokines, resulting in tissue breakdown, uterine bleeding, and dysmenorrhea. ${ }^{1}$ This mechanism of endometrial bleeding is similar to that occurring during the menstrual cycle when premenstrual progesterone withdrawal leads to increased prostaglandin (PG) production and local hypoxia in the endometrium. The combination of all these factors causes the upregulation of endometrial interleukin (IL)-8 production by activating the same NF- $\kappa B$ pathway; however, this only occurs in the secretory or progestin-primed endometrium. ${ }^{2}$

In patients using oral contraceptives in continuous regimens, the occurrence of breakthrough bleeding is associated with the resumption of dysmenorrhea. When this occurs, the inflammatory cascade is stimulated in the endometrium, leading to an intensification of Cox-2 expression through activation of the NF- $\mathrm{KB}$ pathway in a similar way to that occurring during progestin withdrawal bleeding. ${ }^{3,4}$ The concomitant use of 
a natural NF- $\mathrm{BB}$ inhibitor, pycnogenol, not only eliminated the bothersome uterine bleeding in endometriosis patients using oral contraceptives in a continuous regimen, but also further decreased pain scores. ${ }^{5}$ These results suggest that if pycnogenol is used concomitantly with oral contraceptives in cyclic regimens, it may effectively decrease the menstrual pain that can occur during the hormone-free interval. This can be advantageous to some women with severe dysmenorrhea who prefer monthly withdrawal bleeding but would like to avoid the associated pain. In the present paper, the effect of pycnogenol was investigated in women with severe dysmenorrhea using a low-dose oral contraceptive containing gestodene, used in a 24/4-day cyclic regimen.

\section{Patients and methods}

Twenty-four patients with severe dysmenorrhea who had used 21/7-day cyclic oral contraceptive regimens in the past and reported pelvic pain during the hormone-free interval were enrolled for this study. The mean age of these patients was 29 \pm 7 years (mean \pm SD) (range 17-38 years) and their body mass index was $23 \pm 5 \mathrm{~kg} / \mathrm{m}^{2}$ (range $18-28 \mathrm{~kg} / \mathrm{m}^{2}$ ). Patients were randomly allocated to one of two treatment groups according to the order in which they consulted at the clinic. In Group A ( $n=13)$, women were treated with an oral contraceptive containing $15 \mu \mathrm{g}$ of ethinyl estradiol and $60 \mathrm{mg}$ of gestodene (Adoless ${ }^{\circledR}$, Farmoquimica S.A., Rio de Janeiro, Brazil) in a 24/4-day regimen for three consecutive cycles. Women in Group B $(n=11)$ used the same contraceptive regimen together with $100 \mathrm{mg}$ of pycnogenol $\left(\right.$ Flebon ${ }^{\circledR}$, Farmoquimica S.A.) continuously for 3 months. Pain scores were graded using a visual analog scale (VAS) during the hormone-free interval, prior to the initiation of treatment and after the third treatment cycle. Only patients with pain scores above 5 were included. Although the participants were free to use analgesics during the hormone-free interval, pain scores were always recorded prior to the use of any painkillers, if required. Patients who had contraindications to oral contraceptive use according to the World Health Organization's medical eligibility criteria for contraceptive use were excluded from the study. All patients enrolled underwent pretreatment transvaginal ultrasonography. All had regular ovulatory cycles and did not wish to become pregnant.

The study was approved by the internal review board of the Instituto da Mulher, Itaigara Memorial Day Hospital, and all patients gave their informed consent to participate in the study. Statistical analysis was performed using Student's $t$-test to establish differences between mean pain scores prior to the initiation of therapy and following 3 months of treatment, with significance defined as $P$-values $<0.05$. The $t$-test was used because the values were paired. The same statistical analysis was used to detect differences in mean pain scores between Groups A and B, prior to the initiation of treatment and after 3 months of treatment, since these populations were equally distributed.

\section{Results}

Before treatment, all patients had severe dysmenorrhea that had failed to respond to previous treatment with oral contraceptives used in the classic 21/7-day cyclic regimen. There was no statistically significant difference in VAS pain score between the two groups of patients prior to treatment, with pain scores of 8 and 9 in groups $A$ and $B$ respectively $(P=0.13)$. In Group $\mathrm{A}$, endometriosis had been previously diagnosed in $6 / 13$ of the patients compared to $5 / 11$ patients in Group B $(P=0.9)$. Pain scores during the 4-day hormone-free interval had decreased significantly in both groups at the end of the third treatment cycle compared to pretreatment levels, with mean scores of 6 and 2 in groups A and B, respectively. Although both treatments significantly reduced dysmenorrhea by the end of the third cycle, the reduction in pain scores was significantly greater in the pycnogenol + oral contraceptive group (Group B) compared to Group A, in which the oral contraceptive pill alone was used $(P=0.0001)$. Furthermore, $3 / 11$ patients in Group B $(27 \%)$ reported no pain at all during the third hormone-free interval, while all the patients in Group A were still reporting some pain. This difference was statistically significant $(P=0.04)$. The use of analgesics was reported by three patients in Group $A$, whereas none of the patients in group B had any need for painkillers.

\section{Discussion}

Menstrual bleeding is triggered by progesterone withdrawal following the demise of the corpus luteum, which, sequentially stimulates inflammation and PG production in the endometrium through activation of the NF- $\mathrm{KB}$ pathway. ${ }^{6} \mathrm{~A}$ similar mechanism is also triggered by the blockade of progesterone receptors, using the same pathway to induce the translation of target genes related to the inflammatory cascade, including Cox-2. ${ }^{7}$ The subsequent increase in PG production facilitates endometrial breakdown and positively influences the intensity of dysmenorrhea and bleeding. ${ }^{1}$ As a result, hormone-related symptoms are significantly worse during the hormone-free interval than during the days of contraceptive use, and this is a direct consequence of the stimulation of endometrial inflammation. ${ }^{1}$ Extending the standard 21-day cyclic regimen by eliminating the hormone-free interval increases the time 
between the bleeding episodes provoked by progestin withdrawal and decreases menstrual-related symptoms. A recent Cochrane review reported that menstrual symptoms such as pain improved during extended or continuous regimens compared to the conventional 21/7-day cyclic regimen. ${ }^{8}$ Reducing the hormone-free interval from 7 to 4 days will likewise diminish the intensity of menstrual symptoms. ${ }^{9}$ This was also confirmed in the present study, in which results showed a significant reduction in menstrual pain during the hormone-free interval in patients using a 24/4-day regimen of contraceptive pills containing gestodene. However, the introduction of pycnogenol further decreased the severity of dysmenorrhea in oral contraceptive users during the 4-day hormone-free interval. It is noteworthy that none of the patients in the oral contraceptive + pycnogenol group had any further need for painkillers. In view of these findings, it would be interesting to investigate whether a similar reduction in pain could be achieved in symptomatic patients using the classic 21/7-day oral contraceptive regimen together with pycnogenol.

It should also be noted that a great number of patients with severe dysmenorrhea in this study who had previously failed to respond to treatment with oral contraceptives used in a cyclic 21/7-day regimen had endometriosis. The continuous administration of pycnogenol blocks activation of NF- $\mathrm{KB}$ following progestin withdrawal, thus decreasing the severity of endometriosis. ${ }^{3}$ This is in agreement with previous studies showing that pycnogenol, a mixture of anthocyanins extracted from the bark of a maritime pine tree (Pinus pinaster), effectively treated dysmenorrhea without blocking ovulation or suppressing menstruation. ${ }^{10}$ Pycnogenol affects the transactivation capacity of NF- $\mathrm{\kappa B}$ without preventing its DNA-binding activity, while progesterone blocks NF- $\mathrm{KB}$ translocation to the cell nuclei, thus acting in a step prior to DNA binding. ${ }^{11}$

The present findings show that adding pycnogenol to a 24/4-day oral contraceptive regimen further decreased the intensity of dysmenorrhea during the hormone-free interval in patients who had previously failed to respond satisfactorily to treatment with oral contraceptives used in a 21/7-day cyclic regimen. This therapeutic effect was probably the result of the blockade of the NF- $\mathrm{KB}$ transactivation activity that occurs following progestin withdrawal. ${ }^{1} \mathrm{NF}-\mathrm{\kappa B}$ is also a pivotal transcription factor involved in the development of endometriosis, since the levels of expression of its inducible genes such as vascular endothelial growth factor (VEGF) and Cox-2 are increased, with a positive correlation having been found with the intensity of dysmenorrhea. ${ }^{12,13}$ Blockade of $\mathrm{NF}-\mathrm{\kappa B}$-inducible genes by pycnogenol is therefore pivotal in decreasing dysmenorrhea following progestin withdrawal, since this will decrease inflammation and the ensuing pain., ${ }^{1,3}$ These findings are in agreement with the present results that the use of a natural NF- $\kappa B$ inhibitor concomitantly with the 24/4-day oral contraceptive regimen significantly decreases pain in patients with severe dysmenorrhea who had previously failed to respond satisfactorily to 21/7-day oral contraceptive regimens.

In conclusion, the present results show that it is possible to reduce pain during the hormone-free interval in patients with severe dysmenorrhea who had previously failed to respond to cyclic 21/7-day regimens by adding pycnogenol to oral contraceptives containing gestodene when the $24 / 4$ regimen is used.

\section{Disclosure}

The medication used in this study was kindly supplied by Farmoquimica S.A., Rio de Janeiro, Brazil. Dr Maia Jr is a speaker for Farmoquimica S.A. The authors have no other conflicts of interest in this work.

\section{References}

1. Maia H Jr, Haddad C, Coelho G, Casoy J. Role of inflammation and aromatase expression in the eutopic endometrium and its relationship with the development of endometriosis. Womens Health (Lond Engl). 2012;8(6):647-658.

2. Maybin JA, Hirani N, Jabbour HN, Critchley HO. Novel roles for hypoxia and prostaglandin E2 in the regulation of IL-8 during endometrial repair. Am J Pathol. 2011;178(3):1245-1256.

3. Maia H Jr, Casoy J, Correia T, Athayde C, Valente J, Coutinho EM. Activation of NF-kappaB and COX-2 expression is associated with breakthrough bleeding in patients using oral contraceptives in extended regimens. Gynecol Endocrinol. 2010;26(4):265-269.

4. Maia H, Correia T, Freitas L, Athayde C, Coutinho EM. Cyclooxygenase-2 expression in the endometrium and its relationship to bleeding in users of continuous oral contraceptives. Gynecol Endocrinol. 2006; 22(2):96-100.

5. Maia H Jr, Haddad C, Casoy J. Combining oral contraceptives with a natural nuclear factor-kappaB inhibitor for the treatment of endometriosis-related pain. Int J Womens Health. 2013;6:35-39.

6. Sugino N, Karube-Harada A, Taketani T, Sakata A, Nakamura Y. Withdrawal of ovarian steroids stimulates prostaglandin F2alpha production through nuclear factor-kappaB activation via oxygen radicals in human endometrial stromal cells: potential relevance to menstruation. J Reprod Dev. 2004;50(2):215-225

7. Li YF, Xu XB, Chen XH, Wei G, He B, Wang JD. The nuclear factor-kB pathway is involved in matrix metalloproteinase- 9 expression in RU486-induced endometrium breakdown in mice. Hum Reprod. 2012; 27(7):2096-2106.

8. Edelman A, Micks E, Gallo MF, Jensen JT, Grimes DA. Continuous or extended cycle vs cyclic use of combined hormonal contraceptives for contraception. Cochrane Database Syst Rev. 2014;7:CD004695.

9. Jacobson JC, Likis FE, Murphy PA. Extended and continuous combined contraceptive regimens for menstrual suppression. J Midwifery Womens Health. 2012;57(6):585-592.

10. Suzuki N, Uebaba K, Kohama T, Moniwa N, Kanayama N, Koike K. French maritime pine bark extract significantly lowers the requirement for analgesic medication in dysmenorrhea: a multicenter, randomized, double-blind, placebo-controlled study. J Reprod Med. 2008;53(5):338-346. 
11. Saliou C, Rimbach G, Moini $\mathrm{H}$, et al. Solar ultraviolet-induced erythema in human skin and nuclear factor-kappa-B-dependent gene expression in keratinocytes are modulated by a French maritime pine bark extract. Free Radic Biol Med. 2001;30(2):154-160.

12. Li B, Chen M, Liu X, Guo SW. Constitutive and tumor necrosis factor- $\alpha$-induced activation of nuclear factor- $\mathrm{\kappa B}$ in adenomyosis and its inhibition by andrographolide. Fertil Steril. 2013;100(2):568-577.
13. Nie J, Lu Y, Liu X, Guo SW. Immunoreactivity of progesterone receptor isoform B, nuclear factor kappaB, and IkappaBalpha in adenomyosis. Fertil Steril. 2009;2(3):886-889.

International Journal of Women's Health

Dovepress

\section{Publish your work in this journal}

The International Journal of Women's Health is an international, peerreviewed open-access journal publishing original research, reports, editorials, reviews and commentaries on all aspects of women's healthcare including gynecology, obstetrics, and breast cancer. The manuscript management system is completely online and includes

a very quick and fair peer-review system, which is all easy to use. Visit http://www.dovepress.com/testimonials.php to read real quotes from published authors.

Submit your manuscript here: http://www.dovepress.com/international-journal-of-womens-health-journal 